\title{
SASKIA CALDERÓN: EL PERFORMANCE COMO PLATAFORMA ARTIVISTA
}

Saskia Calderón: performance as an artivist platform

\section{Amalina Bomnin}

ISSN (imp): 1390-4825

ISSN (e): 2477-9199

Fecha de recepción:03/27/2020

Fecha de aceptación: 04/19/2020 


\section{Resumen:}

La efervescencia de los artivismos, durante los últimos años, luego de que ocuparan un lugar central allá por las décadas de los ' 60 y '70 del pasado siglo, tiene lugar, dentro de un contexto global donde es vital el cuestionamiento sobre la eficacia del arte de cara a temas como la sostenibilidad social, las acuciantes problemáticas de género, raza, territorio, los populismos y las pandemias. En este marco, la obra de la performer ecuatoriana Saskia Calderón, constituye un caso singular de lo que puede ser una propuesta que se erige en "caballo de Troya". El texto subraya lo atípico de su quehacer dentro de un escenario que ha sido reacio a la visibilización del performance, gracias a motivos diversos. Su práctica se articula como obra situada por la pertinencia de sus enfoques y la sutileza de su abordaje como artivismo cívico.

\section{Palabras clave:}

performance, artivismo, política, golosina caníbal, discurso, monumento, cuerpo, público

\section{Abstract:}

The effervescence of artivisms, in the last years, after their importance back in the decades of the '60s and' 70 s of the last century, takes place, within a global context where questioning about the efficiency of art in the face of themes such as social sustainability and the pressing problems of gender, race, territory, populism and pandemics. In this framework, the work of the Ecuadorian performer Saskia Calderón constitutes a unique case of what a proposal that stands as a "Trojan horse" can be. The text underlines the atypical nature of her work within a setting that has been reluctant to make performance visible. Her practice is articulated as a situated work, due to the pertinence of her methods and the subtlety of her approach as civic artivism.

\section{Key Words:}

performance, artivism, politics, cannibal candy, speech, monument, body, public

\section{Biografía de la autora:}

Amalina Bomnin (Cuba, 1971), Crítica de arte, curadora y profesora. Se formó como historiadora del arte en la Uni-versidad de La Habana, Cuba, donde actualmente desarrolla su tesis de doctorado sobre el performance en Ecuador. Dentro de sus curadurías destacan las ediciones 8va y 9na de la Bienal de La Habana, Cuba; y también para varias instituciones ecuatorianas como Museo Antropológico y de Arte Contemporáneo, MAAC. Su trabajo dentro de las disciplinas curatorial y crítica, le han hecho acreedora de varios premios y reconocimientos. En Cuba, dirigió el Centro de Desarrollo de las Artes Visuales de Pinar del Río, institución que se convirtió en referente, gracias a un trabajo sos-tenido de promoción de las artes visuales cubanas. Dentro de la cátedra que dicta en Universidad de las Artes, Ecuador, desarrolla la plataforma pedagógica Laboratorio vitalista de prácticas indisciplinadas, con el propósito de investigar y producir propuestas performativas en torno a problemáticas de diversa índole. 


\section{Poner el cuerpo}

Durante los últimos años que radiqué en Cuba, -dígase finales del pasado siglo, e inicios del XXI-, comencé a experimentar más empatía hacia las prácticas de artes visuales que comentaban de manera candente sobre temas políticos y que, para lograrlo, "pusieron el cuerpo" (Longoni, Bruzzone, 2008, p. 8). Y al usar esta frase quisiera se entendiera que, la referencia se dirige, de manera puntual, a las acciones de los manifestantes que participaron en El Siluetazo, en Buenos Aires, como parte del taller que, allá por los ' 80 , se convirtiera en creación colectiva y de denuncia a los efectos genocidas de la dictadura en Argentina.

¿Será que mi juicio se escora en demasía hacia el uso de la corporalidad? ¿Existían entonces propuestas articuladas, desde otros medios o soportes, igual de felices y comprometidas? Posiblemente estas preguntas alcancen para otro texto; sobre todo, teniendo en cuenta que existen opiniones encontradas respecto a la manera en que se maneja la obra de discurso político hoy día en la isla. No obstante, siguen siendo potentes y arriesgadas, con bastante igualdad de consenso, las de Tania Bruguera, Alexis Esquivel, Carlos Garaicoa, -durante aquellos años que mencionaba-, y más recientemente, las del artivista Luis Manuel Otero Alcántara, OmniZonaFranca, Danilo Maldonado, más conocido como El Sexto, hasta las más recientes iniciativas de artistas y curadores de \#00 Bienal de La Habana en el 2017.

Por estos días, llegaba a mis manos un texto de una colega cubana que, se me antojaba en sintonía con mis sospechas. Alguien, detenida en las posibilidades infinitas del performance arguye que, quizás, sólo desde él, pueda lograrse la imprescindible sinergia entre el artista y su público, inexorable fusión que constata la puesta en marcha de un estado de "destinerrancia derridiana (refiriéndose al texto teatral) que da lugar a un comportamiento indecidible-término también derridiano- indeterminable, diferido, (...) que aproxima con promiscuidad la puesta en escena a la performance" (Bustillo, 2019, p. 4, 5), y que permitiría materializar, cual rito de paso, una liturgia donde todo el que participa puede tomar, en alguna medida, cartas en el asunto.

Y es que los propios cuestionamientos relacionados con las funciones del arte y la educación en la actualidad pasan por atender a su operatividad y eficacia como dispositivos de visibilización y transformación sociopolítica, su predisposición hacia la sostenibilidad, su validez como plataformas que propicien el pensamiento crítico, -más allá de la precautelación de su arista estética, valor de exhibición o mercantil, y cualquier tipo de cualidades que le confieran carácter cultual-. De ahí que se impongan los usos colectivos de la creación como metodologías de impulso cívico en la lucha por los derechos humanos y otras libertades inalienables.

\section{Desmontar los monumentos}

La asociación sensible que realiza Foucault (2002) de los conceptos discurso con monumento, al referirse a cómo el primero traslapa relaciones de poder, alude, al mismo tiempo, a las brechas de su supuesta unidad, concebida apriorísticamente en el tiempo, y que deberá observarse más bien en atención al carácter disperso de las interpretaciones que recibe un mismo fenómeno, y de cara a una pluralidad discursiva.
la positividad de un discurso -como el de la historia natural, de la economía política, o de la medicina clínica- caracteriza su unidad a través del tiempo, y mucho más allá de las obras individuales, de los libros y de los textos. Esta unidad no permite ciertamente decidir quién ha dicho la verdad, quién ha razonado rigurosamente, quién se ha conformado mejor con sus propios postulados (...).
O más exactamente, esta forma de positividad (y las condiciones de ejercicio de la función enunciativa) define un campo en el que pueden eventualmente desplegarse identidades formales, continuidades temáticas, traslaciones de conceptos, juegos polémicos. Así, la positividad desempeña el papel de lo que podría llamarse un a priori histórico (Foucault, 2002, p. 215)

¿Cómo se aviene esta consideración con el uso que hace la performance del discurso? La naturaleza posdisciplinar del performance resulta en concesión para ubicarse más allá de cualquier sentido preconcebido de lenguaje. La noción de tiempo se disemina porque la propia sinrazón performativa no intenta construcción alguna que apunte a la existencia de un inicio o fin (eso implicaría asociarlo a una lógica moderna), sino que agencia notables derivaciones identificables con la atomización cronotópica. La idea, o ideas abordadas, se desligan de lecturas apegadas a lo cognitivo porque emergen de la complicidad del cuerpo con otras instancias que no tendrían que devenir, precisamente, de 


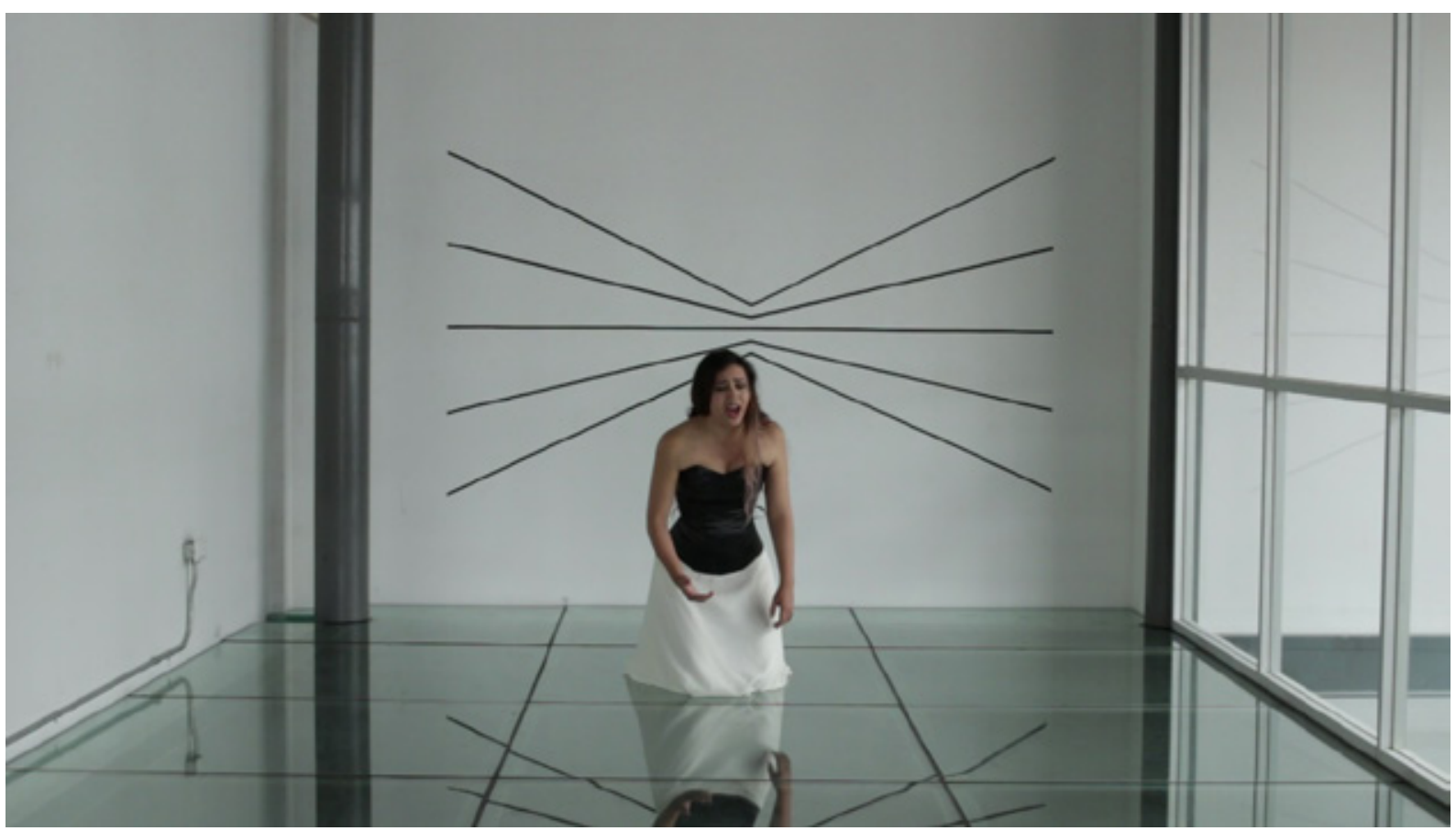

Fig. 1. Saskia Calderón, Disnea melódica, 2019, performance, 12 min.,

Cuando las actitudes devienen performances, Fotografía: Luis Enrique

Bermello

la razón ni de la cultura (aunque éstas pudieran subsistir dentro del texto).

En este sentido, la proyección vitalista de Nietzsche apuntaba al hallazgo del "estatuto autónomo del pensamiento" a través de la búsqueda del "hilo conductor del cuerpo" (Rivero, 2016, p. 87), y tal fundamento debía buscarse en nuestra propia fisiología y en ese "mundo íntimo de fuerzas y de síntomas de un acontecer interior", que es la "voluntad de poder" (Rivero, 2016 p. 87). En opinión de Nietzsche, sólo a partir de un método de comprensión del mundo que tome al cuerpo como pluralidad de perspectivas se abre un camino hacia una manera de pensar no metafísica (Bomnin, 2019, p. 3). Por lo antes señalado, es que advierto en la performance un discurrir en disenso en torno al discurso, en tanto monumento cultural.

La participación de Saskia Calderón (Quito, 1981) en el evento Cuando las actitudes devienen performances, permitió advertir cómo, a través de la utilización de fragmentos de la Constitución de la República del Ecuador, específicamente los relativos al derecho a la integridad personal, donde se alude a una vida libre de violencia en el ámbito público y privado; así como la obligación de adoptar medidas necesarias para prevenir, eliminar y sancionar toda forma de violencia, es posible replantear las dispersiones del discurso. La acción de entonar notas agudas dentro del canto lírico, mientras el corset dificultaba su aliento, activó el contraste entre una puesta en escena perturbadora y el enunciado oficial. Actualmente, Ecuador ostenta el octavo lugar en índice de feminicidios en la región.

En Disnea melódica (2019) (Figura 1), título de la performance mencionada, la artista aparecía vestida de blanco, con corset negro, en una sala vacía, blanca, y piso de vidrio laminado. Este último elemento otorgaba fragilidad a la escena, pues su imagen parecía levitar, gracias a la sensación de vacío que otorga dicho material. De su cuerpo se proyectaban unos puntos de fuga en la pared. La pieza fue performada en el último piso de la Biblioteca de las Artes, en el espacio de la galería.

Hay una serie de investigaciones y pronunciamientos que, desde las llamadas ciencias sociales, han intentado obliterar el alcance de la naturaleza matriarcal de las culturas originarias, y la pervivencia de este sistema en ciertas comunidades actuales. Saskia se apropió de algunos de estos documentos en Mater (2017), un ejercicio que juega a reivindicar no sólo el lugar de lo femenino en el orden universal, sino también los vínculos con la madre tierra consustanciales en dicha organización social. 


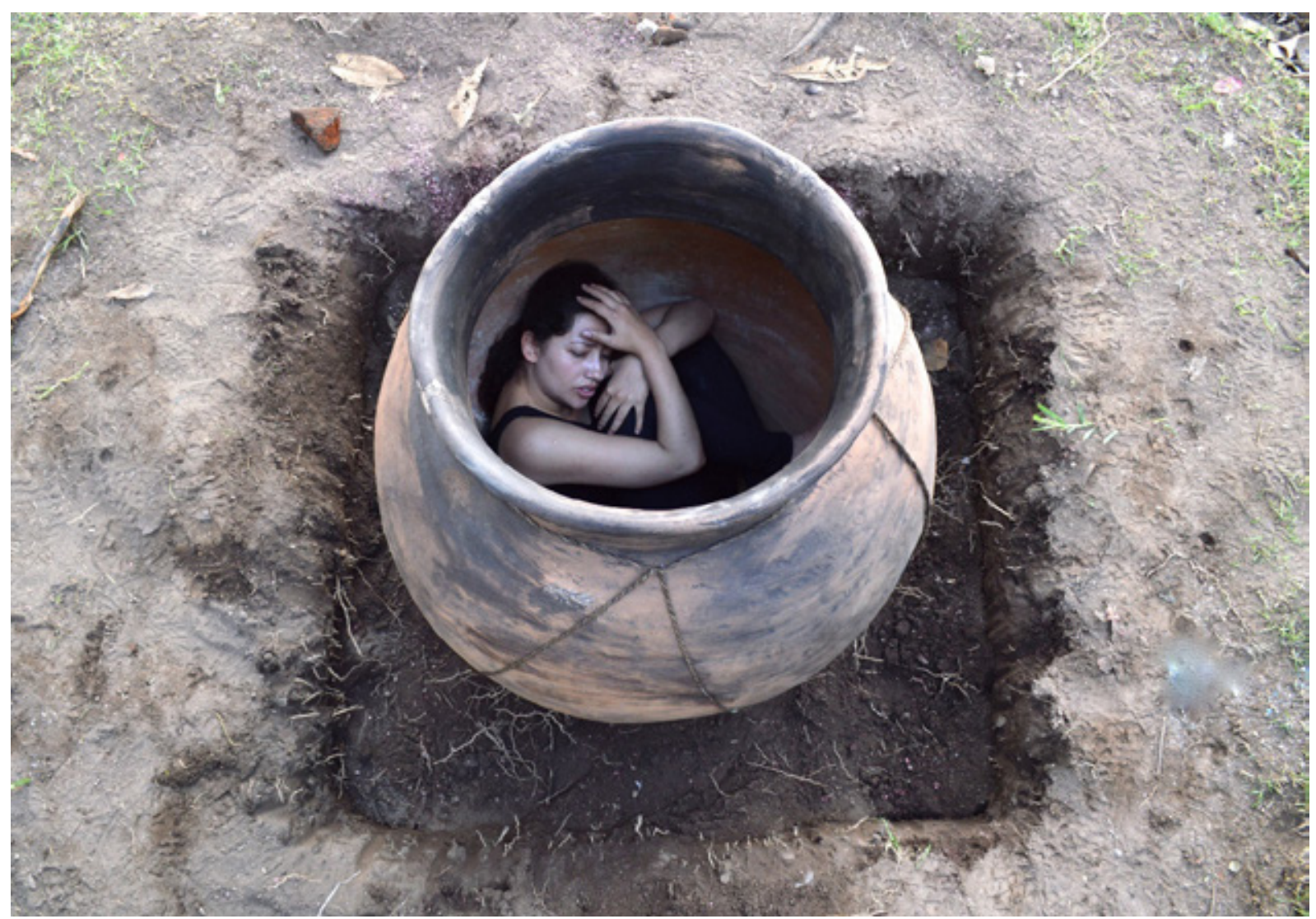

Fig. 2. Saskia Calderón, Mater, 2017, performance, 15 min. "La Intimidad es Politica" curadora: Rosa Martinez. Fotografía: Virginia Calderón

Los procesos de conquista y colonización quebrantaron de manera violenta la creencia de las culturas originarias en el ciclo natural de la existencia: nacimiento-muerte-resurrección al introducir la idea del pecado. Si en su conversión a la fe cristiana o católica el creyente incurría en pecado, recibiría el castigo divino, además de no poder gozar de la vida eterna. La causa primera de tal desliz recayó en la figura femenina, responsable -desde el tamiz religioso ajeno a sus prácticas- de seducir al hombre frívolamente a pecar.

La artista se introdujo en el interior de una olla de barro para adoptar la posición fetal que es común en los enterramientos arcaicos (Figura 2). Desde el interior cantó como si evocara el ritual que garantiza un nuevo nacimiento. Sus melodías enunciaban textos de antropólogos que niegan o minimizan la existencia del matriarcado en la historia e imaginarios ancestrales. La vasija funcionó como vientre, matriz, útero, origen del mundo. También podría leerse como trinchera, perpetuidad del mito, en contraste con la declinación del logo (discurso), que se torna difuso al ser expresado desde el canto lírico.

\section{"Romper los ojos"}

Confieso que mi acercamiento al estudio del performance no hubiese sido el mismo sin la lucidez de Bataille. Tanto le debemos al filósofo por su construcción de nuevos mitos, la aguzada mirada en torno al arte $y$ la vida, y por su defensa a ultranza del cuerpo como esa instancia que advierte más cercana a lo animal que a la propia razón que, seguramente, aún continúo a medio camino respecto al aporte que su legado consigue en el abordaje de la cultura. De más está mencionar cuánto le deben Foucault, Derrida, para no hablar de Lacan.

Desde los relatos En los Mares del Sur, de Stevenson, salidos de su excursión a las islas del Pacífico a fines del XIX, emerge el término "golosina caníbal". ${ }^{1}$ Con él refería el sentido práctico en la búsqueda de alimento por parte de muertos y espíritus al comer los ojos de los viajeros. Esta aproximación al ojo como objeto de seducción y horror es útil a Bataille para construir nuevos mitos. Si éste entrańa pavor y fascinación se le

1 Utilizo el oxímoron de Georges Bataille (quien a su vez lo tomó de Stevenson) para referirme a cómo la imagen exquisita de esta artista tiene la capacidad seductora de atraer al público e introducir sutilmente comentarios cáusticos. 


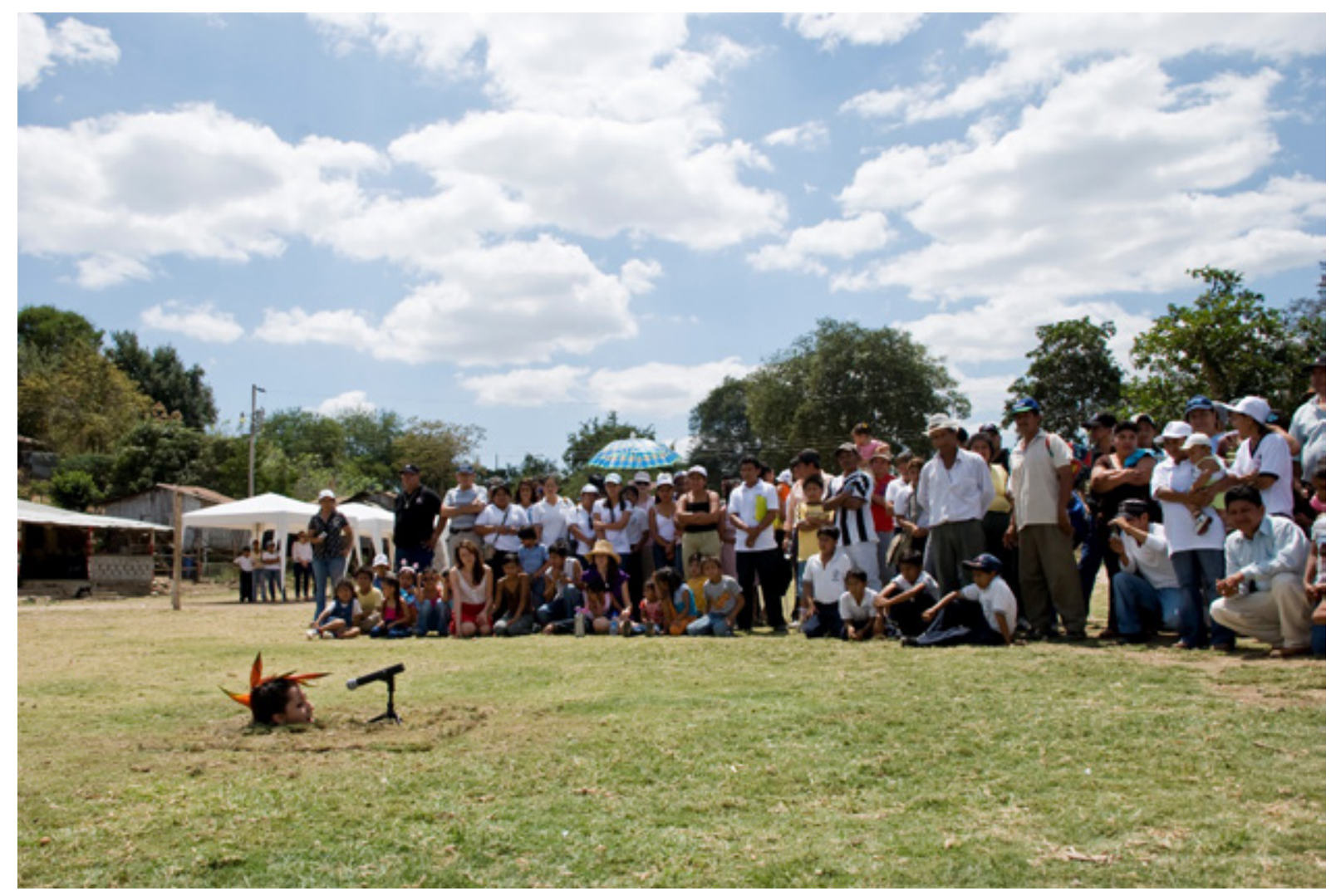

Fig. 3. Saskia Calderón, Gallo despescuezado, performance, 2008, 8 min.,

Fotografia: Javier Lazo

asocia con lo "cortante", pues resguarda la ambivalencia de la atracción o el rechazo; de ahí que Dalí y Buñuel emplearan al ojo cortado en El perro andaluz (1929). Como subraya Assandri en su libro, quizás era propósito de los surrealistas "en tiempos en que había desaparecido la arquitectura académica de la pintura, (...) romper los ojos" (Assandri, 2013, p. 43). Efectivamente, ya Bataille se había referido al hecho de que no sólo "catedrales y palacios inspiraban temor y sabiduría social, sino que también a través de la fisonomía, el vestido, la música, la pintura, se mostraba una arquitectura" (Assandri, 2013, p. 42); que era preciso interpelar para acceder a una visión imparcial.

¿Cómo es que la artista consigue, a través de su práctica, "romper los ojos”? Erigiéndose en "golosina caníbal”. En pocas ocasiones, sobre todo, dentro de la producción del performance latinoamericano, asoman voces con un discurso que se conciba desde la seducción. Abunda la reflexión desde el gesto violento, el shock, o el desgarramiento. Las dos escuelas que conforman la formación de Saskia: artes plásticas y canto lírico, otorgan a esta obra un sentido peculiar de belleza. Resultan la conjugación ideal para que su "puesta en escena” sea leída cual "golosina caníbal”. Su obra se articula como práctica situada, por la pertinencia de los enfoques, y la sutileza de su abordaje como artivismo cívico.

La primera obra de Saskia, sobre la que tuve referencias, fue Gallo despescuezado (Figura 3). Quizás porque la desarrolló en la comunidad Limoncito, como parte de una de las residencias artísticas del proyecto Solo con Natura, dirigido por Larissa Marangoni, donde también colaboré. En esta, se enterró literalmente hasta el cuello; de manera similar a la tradición lúdica de este recinto de la Costa ecuatoriana, durante las fiestas de la Virgen de la Merced, donde usan esta operatoria con un gallo, mientras un comunero intenta cortarle la cabeza con un machete. El que gana se lleva el gallo como trofeo y debe ofrendar otro el año siguiente.

La artista, perturbada al conocer el juego, decide repetir el ritual al mismo tiempo que cantaba problemas y urgencias de los moradores del lugar, los cuales habían sido contadas por ellos a la artista. Y esto la conectaba con aquel proyecto que mantuviera a Bataille y sus colegas ensimismados en su conjuración sagrada: Acéfalo $^{2}$.

2 Acéphale fue un grupo que surge en el contexto de la enemistad de Bataille con Bretón, y al que pertenecieron además 
La sociedad secreta que portó este nombre, el mismo que usaron para la revista que editaron, llevaba por logotipo el dibujo de un cuerpo humano sin cabeza, epítome de la anarquía y caos que había traído aparejado el culto a la modernidad.

El animal es asumido en Bataille como cercanía, justo por alejado de la homogeneizadora racionalidad ilustrada que, en su opinión, coloca al hombre en un estado de encierro y apariencias.

De modo que en cada hombre hay un animal encerrado en una cárcel, como un preso, y hay también una puerta, y si entreabrimos la puerta, el animal se abalanza hacia afuera como el preso que encuentra la salida; entonces, provisoriamente, el hombre cae muerto y el animal se comporta como animal, sin preocupación alguna por suscitar la admiración poética del muerto. En ese sentido se puede considerar al hombre como una cárcel de apariencia burocrática (Bataille, 2008, p. 54).

La práctica artivista de Saskia Calderón se pronuncia como ejercicio situado que anima las posibilidades futuras del género en el país y la región. El hecho de pulsar, desde su propuesta, tópicos dramáticos y urgentes, a partir de lo que Bataille llamaría la arquitectura dentro del paradigma occidental del arte (belleza, simetría, proporciones), convierten su acción en golosina caníbal. Uno de sus aciertos es la continuidad que ha mantenido desde sus primeras piezas, a pesar del escaso espacio que se brinda al medio en el contexto nacional. Cuestión esta última, que intento desbrozar por estos días y donde apelo mientras tanto, a la producción de conocimiento sensible desde la pedagogía, como un camino que nos acerque al "ejercicio de una mística de la alegría frente a la muerte” (Bataille et al, 2010, p. 165).

\section{Referencias}

Assandri, J. (2013). Entre Bataille y Lacan. Ensayo sobre el ojo, golosina canibal, Buenos Aires: El cuenco de plata SRL.

Bataille, G., et al. (2010). Acéphale. Religión, sociología, filosofía. Buenos Aires: Caja Negra Editora.

Bataille, G. (2008). La conjuración sagrada. Ensayos 1929-1939, Buenos Aires: Adriana Hidalgo Editora S.A.

Bomnin, A. (2019). "Bufo: la sinrazón performativa" en Catálogo Bufo. Muestra personal de Virgilio Valero Montalbán, Galería Mirador, Universidad Católica Santiago de Guayaquil.

Bustillo, T. (2019). "Del tiempo y otras temporalidades: simbologías deslizantes en la deconstrucción de una performance", Texto en proceso editorial. Cortesía de la autora.

Longoni, A., Bruzzone, G. (2008). El Siluetazo, Buenos Aires: Adriana Hidalgo Editora.

Foucault, M. (2002). Arqueología del saber, Buenos Aires: Siglo XXI Editores Argentina.

Rivero Weber, P. (coord.) (2016). Nietzsche, el desafío del pensamiento, Ciudad de México, México: Fondo de Cultura Económica.

Bomnin, A. (2 al 4 de abril de 2019). Vivientes. https://antenabomnin.wixsite.com/ vivientes?fbclid=IwAR13sB_CtLGr24zlahQt2nD0J_uXcJ2jRvQDhqgsArHrDKYy9FBSYfCu8c

del primero, Roger Caillois, Pierre Klossowski, André Masson, Jules Monnerot, Jean Rollin y Jean Wahl. Realizaban prácticas esotéricas, artísticas, y de carácter interdisciplinar, aunque fue anunciada como una propuesta de religión, sociología y filosofía, contenidos estos que regularmente publicaban en una revista -bajo el mismo nombre- que surge en 1936, y mantuvo cinco ediciones. 